\title{
Venturing across the Atlantic
}

\author{
Rogier W Rooswinkel, Daan S W Berbers, Eric H J H M Claassen \& Sander van Deventer
}

\section{Is it worth your time to seek overseas investors?}

D. rug development is a risky and costly exercise. Whereas big pharma is able to finance the high costs of research and development (R\&D) and clinical development from revenues of marketed products, small biotech companies typically are funded by venture capital. However, attracting venture capital can be difficult as most venture capitalists (VCs) fund fewer than $1 \%$ of the deals they review ${ }^{1}$. Despite a surge in available venture capital and a thriving US initial public offering (IPO) market in recent years, this low hit rate has not changed much ${ }^{2}$. Rather, more capital has been invested in the same number of companies ${ }^{3}$.

One way to increase the chances of funding would be to use a shotgun fundraising approach and contact investors all across the world. In support of this idea, biotech is a global-acting sector, and attracting an investor from a different continent might bring additional benefits. For instance, the amount of capital available in the United States is much larger than that in Europe, and having a US investor on board could be helpful for followon financings or for listing on a US exchange. Likewise, attracting a US VC to a European or Asian biotech might provide access to local networks of key opinion leaders or clinicians or to pharma contacts. Conversely, for US biotech and especially medtech companies, it might also be attractive to have a local European or Asian investor if the companies want to perform clinical trials in these regions or gain earlier access to local markets.

However, most VCs are biased toward investing close to home ${ }^{4}$, and some might never consider, or may lack a mandate for,

Rogier Rooswinkel is an associate and Sander van Deventer is a partner at Forbion Capital Partners, Naarden, the Netherlands. Daan Berbers is an analyst at Biogeneration Ventures, Naarden, the Netherlands. Eric Claassen is professor at Vrije Universiteit, Amsterdam, the Netherlands.

e-mail:Rogier.Rooswinkel@forbion.com
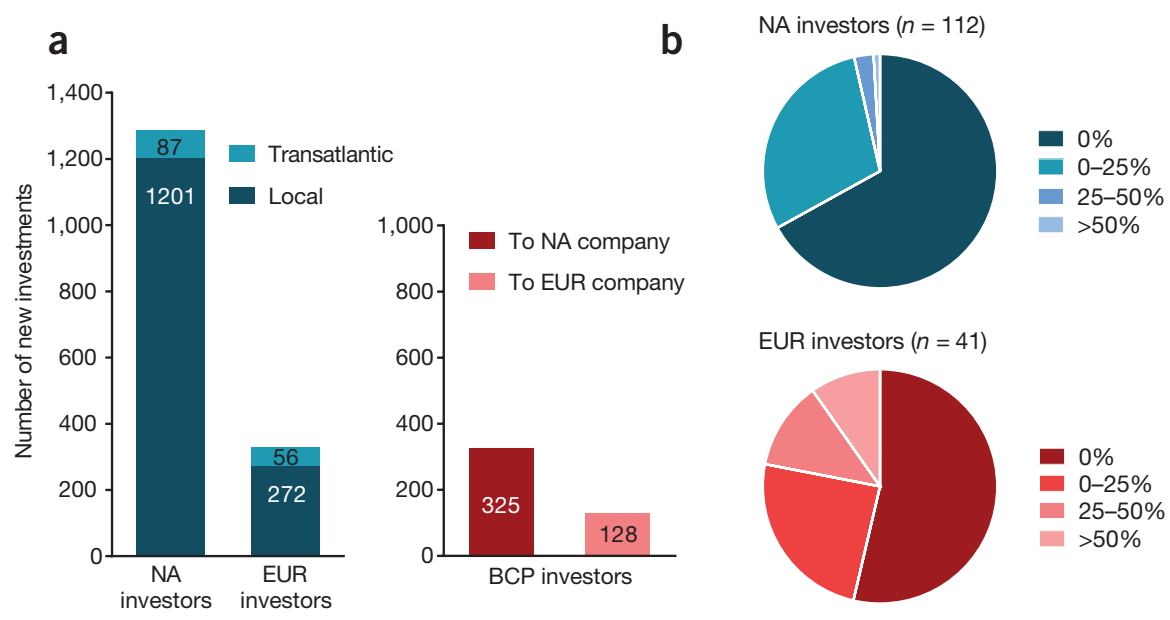

Figure 1 Transatlantic investments are few and far between. (a) Number of local and transatlantic investments by European (EUR) and North American (NA) investors, or investors with a presence in both continents (bicontinental presence (BCP)). (b) Distribution of NA and EUR investors, grouped by their transatlantic investment activity: the number of transatlantic investments as a percentage of all their investments.

investing outside their own locale-whether that's a province, state, country or continent. To optimize the odds for success and help economize time spent on presentations and due diligence, biotech entrepreneurs must focus their fundraising efforts on those VCs that are most likely to invest.

Here, we ask: Is attracting venture capital overseas is worth the effort? If so, what are the requirements? We set out to answer these questions by analyzing the life-sciencefocused venture capital flows within and between Europe and North America, which accounts for $94 \%$ of the venture financings in the BCIQ database.

Our results reveal that transatlantic investments are rather rare and that the vast majority of VCs are active only on one side of the ocean. We also show that VCs tend to invest at a later stage of development and in larger round sizes when considering overseas companies. We hope the data we present will be of help to bioentrepreneurs in their VC-targeting strategy.

\section{The water is wide}

Our dataset was curated according to the methodology detailed in Box 1. It comprises 2,069 new venture investments carried out by 181 active investors across Europe and North America. We analyzed the deal set for local and transatlantic investments (Fig. 1). Not unexpectedly, we found a large difference in the number of active investors and investments between the two regions: there were 2.7 -fold as many active life science investors in North America as in Europe, and only $23.5 \%$ of all new investments in the two sectors were in European ventures. This is in line with previous reports showing a larger quantity of capital being invested in North America year after year ${ }^{2}$.

For the period 2011-2015, North American investors made fewer than $7 \%$ of their 1,288 new investments in Europe (Fig. 1a). In contrast, European investors made slightly over $17 \%$ of their 328 investments across the Atlantic. Interestingly, investors that have offices in both Europe and North America- 


\section{Box 1 Methodology}

Our analysis made use of the BioCentury Online Intelligence database, which tracks biotech companies, their products and the financing they receive around the globe. We extracted all venture financings from the database in the form of VC-company pairs, for all private companies that were located in Europe and North America. The resulting set was curated to contain only first-time investments that were done over a 5-year period (2011-2015). All investors that did not complete at least five novel biotech investments in that period were deemed inactive and hence discarded. As the BioCentury database does not track investor locations, these were added manually. When an investor had offices in both the United States and Europe with permanent presence of at least one lifescience-focused partner, it was considered to have bicontinental presence (BCP). These investments were treated as a separate category.

referred to as investors with bicontinental presence (BCP) - tended to do more (28\%) of their investing in Europe than did North American investors. Together, these data points hint at a much stronger preference on the part of North American investors to invest locally than exists among BCP or European investors. Indeed, $67 \%$ of the 112 North American investors analyzed had not made a single new European investment in the life sciences in the past 5 years (Fig. 1b). This set of investors includes state-specific funds like Connecticut Innovations, which have specific mandates to support local development, but it also includes large, active VCs like Third Rock Ventures (Cambridge, MA) and Domain Associates (Princeton, NJ), which seem to prefer to invest exclusively within North America.

Likewise, $>50 \%$ of the active European investors had not invested in a US company in the study period. These data clearly indicate that biotech start-ups should carefully pick the investors they target in their fundraising efforts and should inform themselves early on about possible geographical mandates or preferences. To help biotech entrepreneurs with this selection process, we have listed alphabetically the ten investors that made most of the transatlantic investments for both North America and Europe, as determined using BioCentury's BCIQ database (Table 1).

\section{Geographical preference}

We subsequently asked whether transatlantic investors might have different geographical preferences than do investors making their investments closer to home. To answer this question we zoomed in to the state or province level in North America and to the country level in Europe. For North America, there were no major differences between European, BCP or North American investors (see also Supplementary Fig. 1): all investors predominantly invested in the big biotech hubs in Massachusetts and California, with around $65 \%$ of their North American investments being in those two states alone. Pennsylvania, Washington and New York followed considerably behind. In Canada, Quebec was the most popular province, accounting for around 2\% of North American investments. The single, small difference observed is that European investors preferred Massachusetts to California, whereas for the locally acting investors this preference was reversed. This could be related to practical considerations concerning time-zone differences and travel time, which might make West Coast investments slightly less attractive to Europeans than those on the East Coast of the United States.

For European investments, the differences are more obvious: whereas European investors spread their investments rather equally over the Western European countries, with only a slight preference for the UK, both North American and BCP investors made close to half of their investments in the UK (Fig. 2). The preference for the UK is perhaps not that surprising, given that North American investors and UK biotechs share the same native language, corporate structures and business culture. The United Kingdom is known for its centers of scientific excellence in Oxford and Cambridge and is home to large pharma companies AstraZeneca (London, UK) and GlaxoSmithKline (London, UK), along with major presences of pharmas headquartered elsewhere, such as Pfizer (New York), Novartis (Basel, Switzerland), Roche (Basel) and Eisai (Tokyo).

Switzerland was also popular with North American and BCP investors, perhaps because it shares many characteristics with the UK, including scientific centers of excellence and being home to large pharma companies Roche and Novartis. A bigger surprise is the lack of investments by North American investors in Germany. Germany is an economically prosperous country, with the highest gross domestic product in Europe. It also has a big pharma presence, including the headquarters of Bayer (Leverkusen, Germany), Boehringer Ingelheim (Ingelheim, Germany) and Merck KGaA (Darmstadt, Germany). Nonetheless, North American investors made only 1\% of their European investments in Germany, as compared with 16\% for European VCs.

Table 1 VCs investing across the Atlantic, 2011-2015

\begin{tabular}{lccc} 
Firm & Local deals & Transatlantic deals & Percentage \\
\hline North American VCs & & & \\
\hline Atlas Venture & 18 & 3 & $14 \%$ \\
\hline Baxter International & 9 & 4 & $31 \%$ \\
\hline MP Healthcare Venture Management & 4 & 3 & $43 \%$ \\
\hline New Enterprise Associates & 31 & 7 & $18 \%$ \\
\hline New Science Ventures & 3 & 5 & $63 \%$ \\
\hline OrbiMed Advisors & 42 & 9 & $18 \%$ \\
\hline Pfizer & 18 & 4 & $18 \%$ \\
\hline RA Capital Management & 40 & 3 & $7 \%$ \\
\hline Rock Springs Capital & 24 & 5 & $22 \%$ \\
\hline Sofinnova Ventures & 21 & 6 & $22 \%$ \\
\hline European VCs & & & $50 \%$ \\
\hline Advent Venture Partners & 4 & 4 & $20 \%$ \\
\hline Forbion Capital Partners & 12 & 3 & $60 \%$ \\
\hline HBM Healthcare Investments & 2 & 3 & $33 \%$ \\
\hline HealthCap & 6 & 3 & $33 \%$ \\
\hline Index (Medicxi) Ventures & 6 & 3 & $57 \%$ \\
\hline Lundbeckford Ventures & 6 & 8 & $100 \%$ \\
\hline Nextech Invest & 0 & 8 & $75 \%$ \\
\hline Shire & 2 & 6 & $18 \%$ \\
\hline Sofinnova Partners & 9 & 2 & $33 \%$ \\
\hline Woodford Investment Management & 8 & 4 & \\
\hline
\end{tabular}




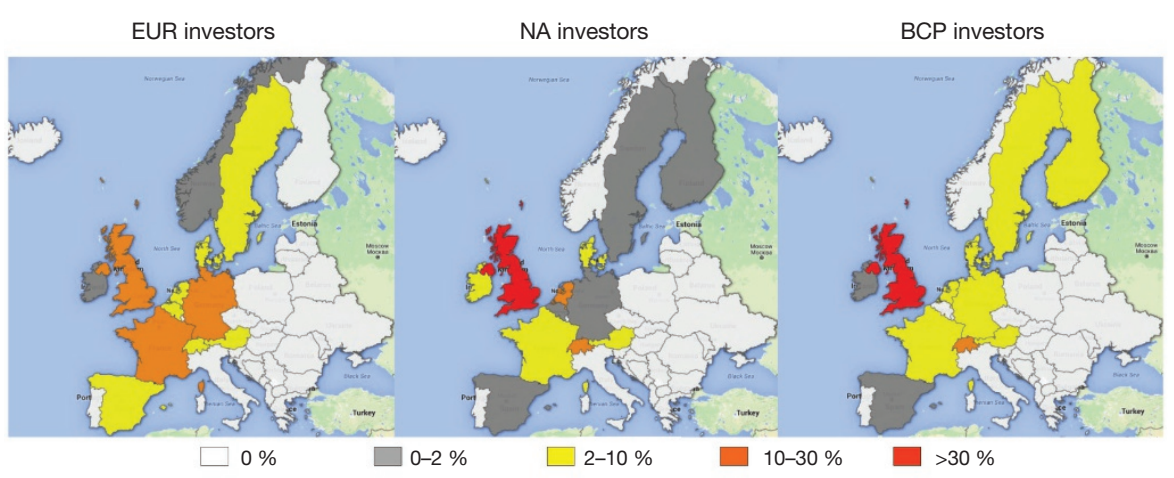

Figure 2 Differential geographical focus between North American and European investors. Map of Europe depicting the investments of European (EUR), North American (NA) and bicontinental presence $(B C P)$ investors. Color coding indicates investments in that country as a percentage of all European investments. Maps were constructed using Google Fusion Tables.

We do not know for certain why North American investors are less willing to deploy capital in Germany than European investors, but we can think of a couple of possible reasons. First, the corporate legal system in Germany is focused more on stakeholders than on shareholders (including, for instance, taxation of stock options) and provides less flexibility than those of some neighboring countries $^{5}$. Most of the North American investors would therefore probably be looking to invest alongside a German venture capitalist with an international focus, of which there are only a limited number in the biotech space. Second, the European Investment Fund (Luxembourg) is a limited partner in many European investment funds, and part of the capital it provides is specifically earmarked for Germany. Lastly, Germany has a substantial number of family offices and wealthy individuals that invest in the local biotech scene. Indeed, $>60 \%$ of European investments into Germany come from within Germany.

\section{Later, bigger and more mature}

Next, we asked whether investors have different criteria for new local as compared to transatlantic investments by comparing the respective deal characteristics. These results could guide bioentrepreneurs toward adapting their financing requests to better serve transatlantic investors or to start fundraising only when certain milestones have been achieved.

We first looked at stages of development. Although both local and transatlantic investments were made at all clinical stages, it is clear that both European and North American investors tended to do more preclinical investing on their home turf (Fig. 3). As the risk of failure within biotech development decreases sharply with every clinical hurdle that is overcome $^{6}$, this may point to a preference for lower-risk opportunities for transatlantic investments, as a means of offsetting potential disadvantages of an investment at a large distance.

Second, more mature companies typically require less hands-on involvement from VCs, which might make them be more suitable for a long-distance financial relationship and require less travel. In line with this view, BCP investors had an almost identical distribution of their first-time investments over the different clinical stages for both North America and Europe (Fig. 3b). This shows that a lack of early-stage transatlantic invest-
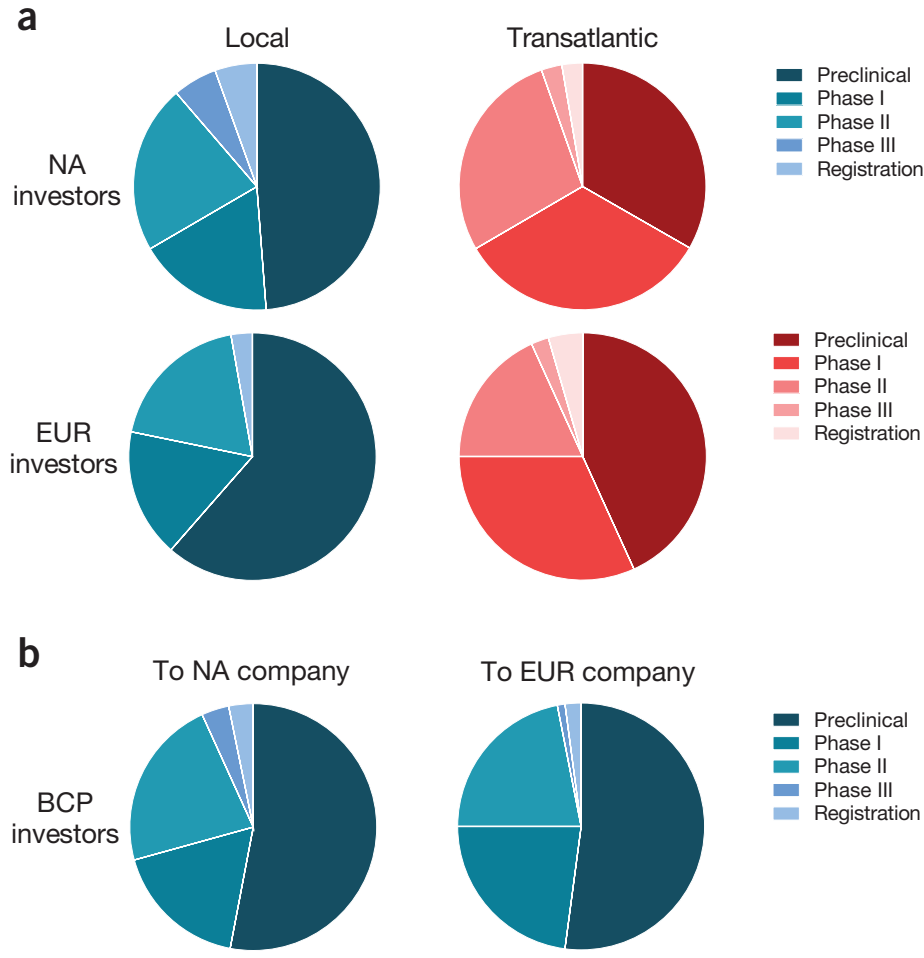

Figure 3 Percentage of investments per clinical phase per investment category. The figure shows local (blue) and transatlantic (red) investments for US and EUR investors (a) and investors with a bicontinental presence in US and EUR companies (b). 


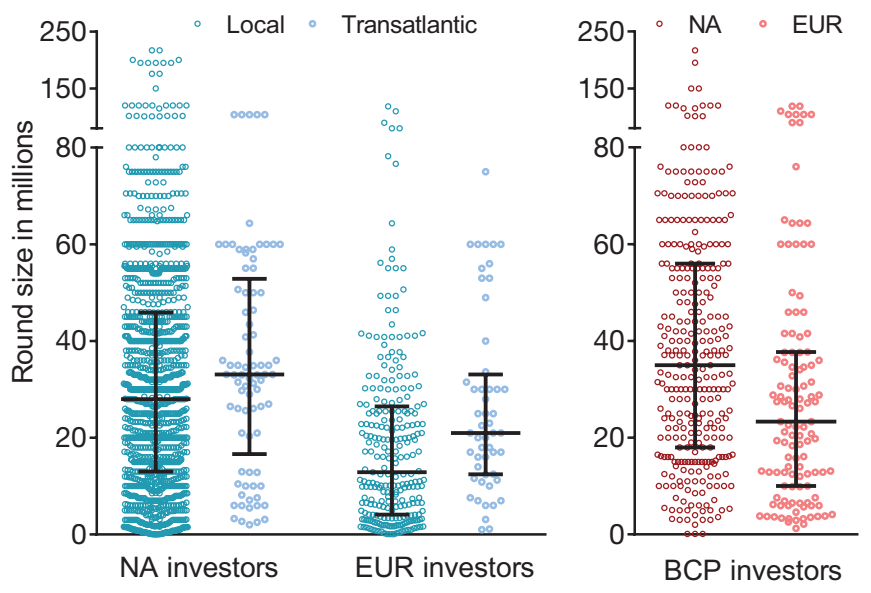

Figure 4 Median round size of the investment rounds per investment category. Each dot represents one investment, and the bars represent median and interquartile ranges. For NA and EUR investors the local and transatlantic investments and bicontinental presence investors' investments in US and EUR companies are displayed.

this probably also reflects their stepping in at a later stage of development (Fig. 3), when rounds sizes typically are larger. For North American investors, we observe the same: whereas the median round size at the moment of their new local investment was $\$ 28$ million, their European contributions were at a median round size of $\$ 33.1$ million. This occurred despite the generally lower round sizes in Europe. In summary, investments both local and transatlantic happen at all round sizes, but transatlantic investments are typically in larger-size rounds.

We also assessed whether there was any indication of preference when investing locally or across the Atlantic. Because of the small sample sizes-for example, the number of European investor deals into US dermatology companies is only 4-we cannot say differences in the data are compelling. These totals are likely to be influenced more by the number of startups available for investment than by a preference for overseas investing by VCs.

\section{Conclusions}

Having transatlantic VCs join your company is attractive from many perspectives, and reaching out to them in a fundraising effort might be a smart move. However, our data show that the number of actual transatlantic investments is fairly low, and that the majority of VCs have not concluded a transatlantic investment for quite a while. Bioentrepreneurs should investigate up front whether the Atlantic Ocean is a surmountable hurdle for the VC they intend to contact, and focus efforts on VCs with a proven transatlantic track record. There is no absolute cut-off on the stage of development or size of venture round, and transatlantic investments are being done across all stages. Nonetheless, North American and European investors prefer more advanced companies and larger rounds for their transatlantic investments. Finally, many VCs consider financing rounds only where there is a 'local lead investor' or an existing local investor base, who can do a large part of the due diligence work and support the company hands-on.

Note: Any Supplementary Information and Source Data files are available in the online version of the paper.

\section{COMPETING FINANCIAL INTERESTS}

The authors declare competing financial interests: details are available in the online version of the paper.

1. Gompers, P., Gornall, W., Kaplan, S.N. \& Strebulaev, I.A How Do Venture Capitalists Make Decisions? (National Bureau of Economic Research, 2016).

2. EY. Biotechnology Investor Report 2025: Beyond Borders: Reaching New Heights (EY, 2015).

3. Booth, B. The venture funding boom in biotech: a few things it's not [blog] http://lifescivc.com/2015/07/theventure-funding-boom-in-biotech-a-few-things-its-not/ (2013).

4. Cumming, D. \& Dai, N. Local bias in venture capital investments. J. Empir. Finance 17, 362-380 (2010).

5. Odenius, J. IMF Working Paper: Germany's Corporate Governance Reforms: Has the System Become Flexible Enough? (IMF, 2008)

6. Hay, M., Thomas, D.M., Craighead, J.L., Economides, C. \& Rosenthal, J. Clinical development success rates for investigational drugs. Nat. Biotechnol. 32, 40-51 (2014). 